\title{
Nanofibrillated cellulose and cellulosic pulp for reinforcement of the extruded cement based materials
}

\author{
Viviane da Costa Correia ${ }^{\mathrm{a}, *}$, Sergio Francisco Santos ${ }^{\mathrm{b}}$, Ronaldo Soares Teixeira ${ }^{\mathrm{a}}$, Holmer Savastano Junior ${ }^{\mathrm{a}}$ \\ ${ }^{a}$ Department of Biosystems Engineering - Faculty of Animal Science and Food Engineering, University of Sao Paulo, Duque de Caxias Norte Street, 225, 13630-000 Pirassununga, \\ SP, Brazil \\ ${ }^{\mathrm{b}}$ Department of Materials and Technology - Faculty of Engineering, Sao Paulo State University, Ariberto Pereira da Cunha, 333, 12516-410 Guaratinguetá, SP, Brazil
}

\section{H I G H L I G H T S}

- The high specific surface area of NC improves the fiber-matrix bonding.

- The NC improves the stress transfer when the composite is subjected to load.

- At 28 days the hybrid composite presents a higher modulus of rupture. - In the hybrid composite, the NC acts as nanoreinforcement after accelerated ageing.

\section{A R T I C L E I N F O}

\section{Article history:}

Received 17 January 2017

Received in revised form 29 September 2017

Accepted 14 November 2017

Available online 21 November 2017

\section{Keywords:}

Nanofibrillated cellulose

Nanoreinforcement

Hybrid reinforcement

Cementitious materials

Durability
G R A P H I C A L A B S T R A C T

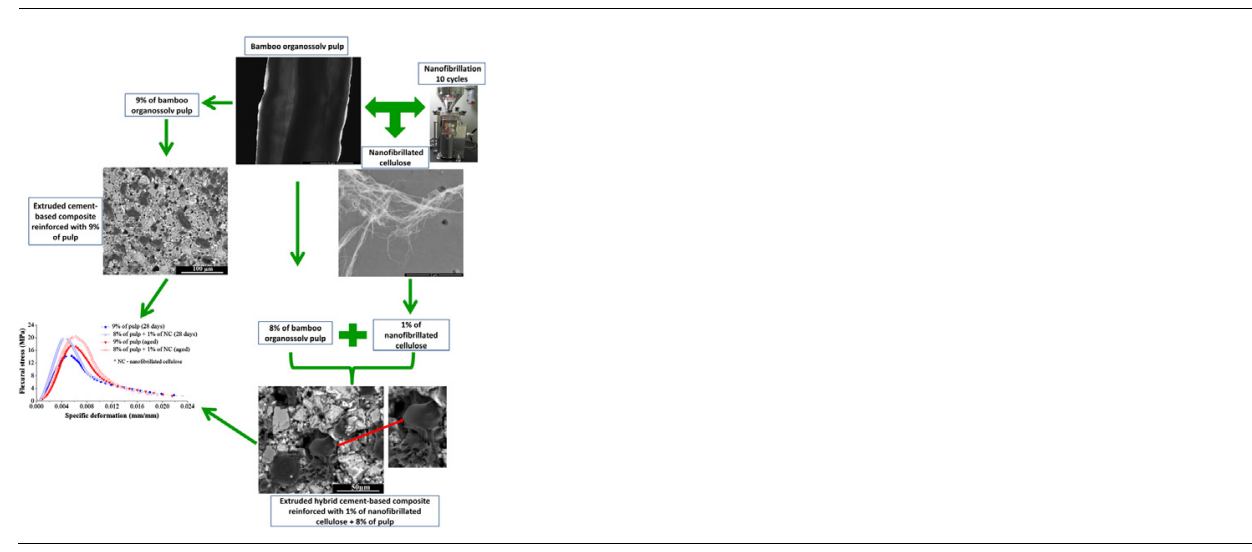

\begin{abstract}
A B S T R A C T
The use of cellulose nanofibers as reinforcement may contribute for improving particle packing and decrease the crack growth rate of composites at nanoscale. Additionally, the high specific surface area of cellulose nanofibers contributes to improve the adhesion between the cement particles. Thus, the aim of this work was the study the performance of hybrid composites reinforced with $8 \%$ pulp and $1 \%$ nanofibrillated cellulose compared to composites reinforced with only $9 \%$ of pulp produced by the extrusion process. The accelerated aging process by means of 200 wet and dry cycles was carried out to assess composite degradation. In the hybrid composites the nanofibrillated cellulose improved the mechanical behavior compared to the composite without nanofiber. This improvement may be associated with greater adherence between the nanofibrils and the cement matrix. After accelerated ageing, the composites with and without nanofibers showed no reduction in mechanical performance, which is attributed to the lower alkalinity provided by the accelerated carbonation. Therefore, the nanofibrillated cellulose showed to be a promising material for use as nanoreinforcement of the extruded hybrid cement-based composites.
\end{abstract}

(c) 2017 Elsevier Ltd. All rights reserved.

\footnotetext{
* Corresponding author.

E-mail address: vivianecostcor@usp.br (V. da Costa Correia).
}

\section{Introduction}

The cementitious materials are ceramic that originally present a brittle behavior when is subjected to a load i.e. it presents a yield strength similar to tensile strength. A brittle fracture initially takes 
place at the nano and/or interatomic scales without prior plastic deformation during elastic loading, because the ions-covalent bonds of ceramics do not allow the movement of the dislocations at room temperature due the electrostatic restrictions. In fibercement it is important to consider the nanomechanical behavior of the calcium silicate hydrate $(\mathrm{C}-\mathrm{S}-\mathrm{H})$, the binding phase in all cementitious materials, is one of the most complicated and intriguing material systems in materials science and engineering $[1,2]$.

A means of minimize the problem of cracking is through the incorporation of fibers in the cementitious matrix, and consequently the toughness, flexural strength, resistance to cracking and crack propagation are improved. The main advantage of the use of fibers as reinforcement of the cementitious materials is in it post-cracking behavior [3-6]. In this way, mechanical behavior of fiber-cement composites is also characterized by an interfacial transition zone in the vicinity of the reinforcing inclusion, in which the microstructure of the matrix is considerably different from that of the bulk matrix, away from the interface.

The incorporation of nanofibers in the cementitious matrix is a partial solution to the challenge of the cracking, due the nanofibers acting as stress transfer bridges in the nano-cracking. Many studies have been conducted about the use of the nanofibers and carbon nanotubes [7-9], which act as bridges over the cracks in order to create reinforcement mechanisms and to retard cracking in the nanoscale. Thus, there are improvements in flexural and compressive strength of these materials [10-16].

\subsection{Nanofibrillated cellulose}

The nanofibers from vegetable origin are an alternative for use as nanoscale reinforcement of cementitious materials, since they have additional advantages, such as, abundance worldwide, renewable, have low density and high mechanical strength and stiffness [17-21].

A method for obtaining vegetable nanofibres is the mechanical nanofibrillation. This method causes irreversible changes in the fibers by isolating cell wall. The nanofibrillation occurs from the use of shear force without the need for chemicals, such as hydrolysis in acid. Mechanical fibrillation increases the potential for bonding by modifying the morphology and reducing the size of the fibers [21-23].

According to Ardanuy et al. [24] the high specific surface area of the nanofibrillated cellulose provides a good fiber-matrix bonding. Furthermore, the increase of hydroxyl groups available on the cellulose enables the formation of the hydrogen bonds between nanofibrillated cellulose and cementitious matrix.

\subsection{Inorganic matrices reinforced with nanofibrillated cellulose}

Some studies have been reported the use of cellulose nanofibers as reinforcing cementitious materials. Ardunay et al. [24] used 3.3\% (by mass) of nanofibrillated cellulose from sisal as reinforcement of mortar. The authors reported an increase of the $26.4 \%$ in the flexural strength and $41.5 \%$ in the modulus of elasticity in the mortar reinforced with nanofibrillated cellulose in comparison to mortar reinforced with the pulp.

Onuaguluchi et al. [25] produced cement pastes by the incorporating of nanofibrillated cellulose from bleached pine pulp at levels of $0.05 \%, 0.1 \%, 0.2 \%$ and $0.4 \%$. The results showed that the pastes reinforced with $0.1 \%$ of nanofibers presented an increase of $106 \%$ in flexural strength and $184 \%$ in energy absorption, comparing to pastes without nanofiber.

The results of this work show that the use of fibers at the nanometer scale is effective for increasing the mechanical performance of cementitious materials. Additionally, in hybrid composites, two or more fibers with different characteristics and scales are combined to produce a new material, which derives benefits of each individual fiber and displays a synergistic response [26].

In the hybrid composite, microfibers in the pulp form can contribute to a better packing in the cementitious matrix. Hence, it is possible to use higher fiber contents of around $10 \%$ by mass, with a good anchoring of the fiber in the matrix and higher number of filaments for a given volume of reinforcement, resulting in improvements in the flexural strength and toughness [27-29].

The fibers of different dimensions, in hybrid composites, act to provide a dense packing and with a better dimensional stability, and from the use of micro and nanometric fibers, they work as reinforcements in the corresponding scales and according to their dimensions.

Besides, there is the reduction of lignocellulosic fiber durability is caused mainly by the alkaline ( $\mathrm{pH}$ around 12 ) environment of the cement matrix. The pore water, with high alkalinity, damages the macromolecular chains by means of hydrolysis of the cellulose, which causes their rupture and a consequent decrease of the degree of polymerization of the cellulose chains [30].

The curing process may positively influence the performance of micro and nanometric reinforcements in the cementitious matrix. The accelerated carbonation curing contributes for the refinement of the porous structure and decreasing alkalinity of the cementitious matrix, and thereby there is a better adhesion interface between the particles of the matrix and fibers and better durability of lignocellulosic fibers [31]. As a result there are better stress distribution with nano-reinforcement, densification of the matrix and improvement of the mechanical performance of composites.

Thus, the aim of this study was to evaluate the hybrid cementitious composite reinforced with nanofibrillated cellulose and pulp using as reference composites reinforced only with pulp in order to investigate the effect of the nano-reinforcement in the physical, mechanical and microstructural performance in the extruded composites.

\section{Materials and methodology}

\subsection{Preparation and characterization of pulp and nanofibrillated cellulose}

The pulp was obtained from bamboo by the organosolv pulping method, according to Correia et al. [21,32,33]. The pulp was chemical composed by $1.5 \%$ of extractives, $14.4 \%$ of lignin, $8.8 \%$ of hemicellulose and $76 \%$ of cellulose, which were, respectively, determinated according to Tappi Standards [34,35] and Morais et al. [36].

The nanofibrillated cellulose was produced from unbleached bamboo organosolv pulp by the grinding method, using a commercial grinder, Supermasscolloider Mini, model MKCA 6-2, with two grinding stones of aluminum oxide $\left(\mathrm{Al}_{2} \mathrm{O}_{3}\right)$, model MKGA 6-80\#, produced by Masuko Sangyo Co., Ltd., Japan. The nanofibrillation was produced after 10 nanofibrillation cycles, according to Correia et al. [21].

The average distributions of the length and width of the pulp were analyzed using a Pulptec ${ }^{\mathrm{TM}}$ MFA-500 Morphology Fibre and Shive Analyser - MorFiTrac, according to Tonoli et al. [37] and Correia et al. [33]. The structure and the size of the nanofibrillated cellulose were examined from the images obtained via Scanning Transmission Electron Microscopy (STEM) (FEI Magellan $400 \mathrm{~L}$ Scanning Electron Microscope), according to Correia et al. [21]. The average width of 150 fibers for each sample was measured from the STEM images using the free software for image analysis called ImageJ. The scale of the software was calibrated using the scale bar on the STEM images. 
Table 1

$\mathrm{X}$-ray fluorescence chemical analysis of the particulate raw material (\% by mass).

\begin{tabular}{lll}
\hline Oxide composition & $\begin{array}{l}\text { Ordinary Portland cement } \\
\text { CP V-ARI }\end{array}$ & Limestone filler \\
\hline $\mathrm{SiO}_{2}$ & 19.1 & 1.70 \\
$\mathrm{Al}_{2} \mathrm{O}_{3}$ & 4.44 & 0.21 \\
$\mathrm{Fe}_{2} \mathrm{O}_{3}$ & 2.68 & 0.17 \\
$\mathrm{MnO}$ & $<0.10$ & 0.04 \\
$\mathrm{MgO}$ & 2.32 & 3.04 \\
$\mathrm{CaO}$ & 63.50 & 51.7 \\
$\mathrm{Na}_{2} \mathrm{O}$ & 0.36 & 0.01 \\
$\mathrm{~K}_{2} \mathrm{O}$ & 1.10 & 0.09 \\
$\mathrm{TiO}_{2}$ & 0.24 & 0.03 \\
$\mathrm{P}_{2} \mathrm{O}_{5}$ & 0.21 & 0.08 \\
$\mathrm{SO}_{3}$ & 2.63 & - \\
$\mathrm{SrO}^{\text {Loss on ignition }}$ & 0.14 & 0.14 \\
$\left(1050^{\circ} \mathrm{C}\right)$ & 3.52 & 43.1 \\
\hline
\end{tabular}

The specific density of the pulp and nanofibrillated cellulose was measured by means of gas pycnometer (Quantachrome Instruments, Multipycnometer 1000).

\subsection{Matrix constituents}

The inorganic matrix was composed by the Ordinary Portland cement (OPC) type CP V-ARI correspondent to ASTM-C150 Type I [38] and by the ground limestone filler. The quantitative chemical analysis of OPC and limestone filler was carried out by X-ray fluorescence equipment PANalytical Axios Advanced. The oxide compositions are listed in Table 1 . The loss on ignition is related with the quantity of moisture, impurities, organic matter or $\mathrm{CO}_{2}$ lost in the raw materials at a specified temperature. The specific density of OPC and limestone filler was $3.07 \mathrm{~g} . \mathrm{cm}^{-3}$ and $2.76 \mathrm{~g} . \mathrm{cm}^{-3}$, respectively, which was measured by means of gas pycnometer (Quantachrome, Multipycnometer 1000).

\subsection{Composites production}

The hybrid composites and the composites reinforced only with pulp were produced by the extrusion process. The formulations listed in Table 2 were inspired in the previous work by Correia et al. [33].

The water soluble polymers, hydroxypropyl methylcellulose with 86,000 average molecular weight and $5.39 \mathrm{cP}$ viscosity (at $2 \%$ concentration in water at $20^{\circ} \mathrm{C}$ ), provided by Aditex, and high range water reducer polyether carboxylic (commercially named ADVA 190 and provided by Grace) were used as rheological modifiers to promote pseudo-plastic behavior of the extruded composite. Each additive was applied in the proportion representing $1 \%$ of the total mass of the particulate raw materials, and was required to enable the extrusion process.

The mixture was homogenized in a mechanical intensive mixer high energy from Eirich (capacity of $10 \mathrm{~L}$ ) during $5 \mathrm{~min}$ at high speed. The mixture was transferred to a Gelenski MVIG-05 labora-

Table 2

Composition of the extruded fiber-cement composites.

\begin{tabular}{lll}
\hline \multirow{2}{*}{ Raw materials } & \multicolumn{2}{l}{ Content (\% by mass) } \\
\cline { 2 - 3 } & Formulation 1 & Formulation 2 \\
\hline Ordinary Portland cement (CP V-ARI) & 75 & 75 \\
Limestone filler & 25 & 25 \\
Bamboo organosolv pulp & 8 & 9 \\
Nanofibrillated cellulose & 1 & - \\
W/C ratio & 0.57 & 0.51 \\
\hline
\end{tabular}

tory extruder following the procedures adjusted in previous works $[39,40]$. The linear speed of the extruder was approximately $4 \mathrm{~mm}$. $\mathrm{s}^{-1}$. The mixture was re-circulated into the extruder for 2 times before tailoring the samples. Samples of $200 \mathrm{~mm} \times 50 \mathrm{~mm} \times 15$ $\mathrm{mm}$ were extruded and immediately transferred to the steel plates for initial curing and hardening.

The composites of the both formulations were cured in a total time of 28 days, of wherein, during 2 days the composites were kept in a saturated environment within the hermetically sealed packaging at ambient temperature. After 2 days of initial cure the composites were subjected to accelerated carbonation.

The accelerated carbonation conditions were adopted based on the adaptation of the methodology used by Almeida et al. [31], which was used $15 \%$ of $\mathrm{CO}_{2}$ in a climate chamber at $45^{\circ} \mathrm{C}$ and $70 \%$ of relative humidity during 26 days.

\subsection{Accelerated aging test}

After curing a part of the composites at 28 days was subjected to characterization in dry condition and another part was subjected to accelerated aging test for the evaluation of durability of the composites. The samples were submitted to 200 cycles of immersion and drying (as utilized by Correia et al. [33] and Tonoli et al. [37], based on reccommendations by the EN 494 Standard [41] modified.

The accelerated aging test aims to simulate natural weathering using immersion and drying cycles. The specimens were successively immersed in water at $20 \pm 5^{\circ} \mathrm{C}$ for $170 \mathrm{~min}$ and heated to $60 \pm 2{ }^{\circ} \mathrm{C}$ for $170 \mathrm{~min}$ in a ventilated oven for drying capillary pore system. The samples were then stored at room temperature for 10 min prior to the next cycle. The alternation of the immersion and drying cycles were performed in automatic climate chamber.

\subsection{Mechanical tests}

Mechanical tests were carried out according to methodology adopted by Santos et al. [40]. Prismatic specimens from extruded and cured samples were machined and polished the specimen sides to obtain nominal dimensions of $80 \mathrm{~mm} \times 20 \mathrm{~mm} \times 15$ mm. A servo-hydraulic mechanical testing machine MTS model 370.02, controlled by MultiPurpose TestWare System, was used for perform the mechanical tests. The three-point bending test configuration with span of $64 \mathrm{~mm}$, based on the concepts of fracture mechanics were carried out using a load cell of $2.5 \mathrm{kN}$. Specific type of specimen and parameters of test were used for each mechanical propriety: modulus of rupture (MOR), fracture toughness $\left(\mathrm{K}_{\mathrm{IC}}\right)$ and fracture energy (FE). The fracture toughness and fracture energy were determined using the single-edge notch bend SENB-type specimens.

The modulus of rupture (MOR) was determined using prismatic specimens and test configuration as mentioned previously. The cross-head speed was $5 \mathrm{~mm} / \mathrm{min}$. The Eq. (1) was used in calculation of the MOR.

$\mathrm{MOR}=\left(\frac{3 * \mathrm{P}_{\max } * \mathrm{~L}_{\mathrm{V}}}{2 * \mathrm{~b} * \mathrm{~h}^{2}}\right)$

where $P_{\max }$ is the maximum load value, $L_{v}$ is the major span, $b$ and $h$ are the specimen width and depth respectively.

Fracture toughness, $\mathrm{K}_{\mathrm{IC}}$, was determined to evaluate the initial crack growth resistance in cement matrix. The prismatic specimens were prepared, with a centred flat notch with depth equal to $10 \%$ of the specimen height and notch tip profile in the shape of a "V", with angle of about $30^{\circ}$ using a diamond disc of $0.5 \mathrm{~mm}$ thick to simulate a sharp crack in order to establish the critical defect size and catastrophic fracture. A cross-head speed of 15 
mm/min was applied. According to Santos et al. [40], the Eq. (2) was used in calculation of the $\mathrm{K}_{\mathrm{IC}}$.

$\mathrm{K}_{\mathrm{IC}}=\frac{\mathrm{P}_{\max }}{\mathrm{b} \cdot \mathrm{W}^{1 / 2}} \cdot \mathrm{y}(\propto)$

where $\mathrm{y}(\alpha)$ is a geometric factor. The ratio $\alpha=\mathrm{a} / \mathrm{w}$ of initial notch length to specimen height was 0.1 (or $10 \%$ as mentioned before).

The factor $\mathrm{y}(\alpha)$ is written as:

$$
\begin{aligned}
\mathrm{y}(\alpha)= & \frac{\mathrm{S}}{\mathrm{w}} \cdot\left[\frac{3 \alpha^{1 / 2}}{2(1-\alpha)^{3 / 2}}\right] \\
& \cdot\left[1,99-1,33 \alpha-\left(3,49-0,68 \alpha+1,35 \alpha^{2}\right) \cdot \frac{\alpha(1-\alpha)}{(1+\alpha)^{2}}\right]
\end{aligned}
$$

where $S$ is the span; $\alpha$ is the relative length of the notch, which, in turn, is the ratio of the original length of the notch; and $w$ is the height of the specimen.

The fracture energy was obtained to evaluate the toughness and the interaction between fiber and matrix with stable crack growth rate. The specimens with a centred flat notch with $30 \%$ of specimen height and notch tip in " $\mathrm{V}$ " with angle of about $30^{\circ}$ were prepared using diamond disc of $0.5 \mathrm{~mm}$ thick. A cross-head speed of $10 \mu \mathrm{m}$. $\min ^{-1}$ was adopted and controlled by the actuator displacement to guarantee stable growth of the crack.

According to Santos et al. [40], the work done by the machine to completely propagate the crack along the specimen divided by two times the projected area of the fracture surface (cross-section of the specimen) was used to obtain the fracture energy, $\gamma_{\text {woF. }}$. The integration of the load-displacement curve was made up to the point where the force decreased to $10 \%$ of its maximum value reached during the test.

The dynamic Young's modulus of the composites was measured by impulse excitation of vibration. Prismatic specimens with nominal dimensions of $160 \mathrm{~mm} \times 20 \mathrm{~mm} \times 15 \mathrm{~mm}$ were used. The tests were performed in the flexural vibration mode and the calculation by the Eq. (4) according to ASTM E1876 [42] Standard.

$\mathrm{E}=0,9465\left(\frac{\mathrm{m} * f_{\mathrm{f}}^{2}}{\mathrm{~b}}\right) *\left(\frac{\mathrm{L}^{3}}{\mathrm{t}^{3}}\right) * \mathrm{~T}_{1}$

where $\mathrm{E}$ is the dynamic Young's modulus; $\mathrm{m}$ is the weight of the specimen $(\mathrm{g})$; $\mathrm{L}$ is the length $(\mathrm{mm})$; $\mathrm{b}$ is the width $(\mathrm{mm})$; and $\mathrm{t}$ is the height of the specimen $(\mathrm{mm}) ; \mathrm{f}_{\mathrm{f}}$ is the fundamental flexural resonant frequency $(\mathrm{Hz})$; and $\mathrm{T}_{1}$ is a correction factor for the fundamental flexural mode, which depends on Poisson ratio $(\mu)$ and aspect ratio of the specimen. This correction factor is calculated by the Eq. (5).

$$
\begin{aligned}
\mathrm{T}_{1}= & +6,585 *\left(1+0,0752 * \mu+0,8109 * \mu^{2}\right) *\left(\frac{\mathrm{t}}{\mathrm{L}}\right)^{2} \\
& -0,868 *\left(\frac{\mathrm{t}}{\mathrm{L}}\right)^{4} \\
& -\left[\frac{8,34 *\left(1+0,2023 * \mu+2,173 * \mu^{2}\right) *\left(\frac{\mathrm{t}}{\mathrm{L}}\right)^{4}}{1+6,338 *\left(1+0,1408 * \mu+1,536 * \mu^{2} *\left(\frac{\mathrm{t}}{\mathrm{L}}\right)^{2}\right.}\right]
\end{aligned}
$$

Table 3 shows the number of specimens used for mechanical tests of the hybrid composites and composites reinforced only with pulp at 28 days and after accelerated aging.

\subsection{Physical tests}

Non-destructive physical tests were used to determine the water absorption, bulk density and apparent void volume of the hybrids composites and composites reinforced with pulp, according to ASTM C-948-82 [43] and Correia et al. [33]. At 28 days eight specimens of the hybrid composites, and seven specimens of the composites reinforced with pulp were evaluated. After accelerated aging, six specimens of each type of composite were used.

\subsection{Microstructural analysis of the composites}

Mercury Intrusion Porosimetry (MIP) measurements were used to determine the pore size distribution using a Micromeritics Poresizer 9320 to compare the pore structure of the hybrid composites and composites reinforced with pulp at 28 days and after accelerated aging test.

The conditions of analysis were: mercury pressure up to 200 MPa; stabilization time in the low and high pressure settings of $10 \mathrm{~s}$; an assumed surface tension of $0.485 \mathrm{~N} . \mathrm{m}^{-1}$ and a contact angle of $130^{\circ}$, which was used in the Washburn equation to convert the applied pressure to the pore diameter. Even though this technique loses its accuracy for "ink-bottle" pores and fractures can be possibly induced in samples under high intrusion pressure, according to Diamond [44], the MIP measurement is the preferred method for pore structure evaluation due to its large range of pore size measurements and easy operation [31].

The polished surfaces of the hybrid composites and composites reinforced only with pulp were examined by Scanning Electron Microscopy (SEM) using a FEI Inspect S50. The specific surface area of the nanofibrillated cellulose and its bonds potential was studied, analyzing the surrounding of the fibers and its adherence with matrix. Samples were prepared based on the methodology adopted by Correia et al. [33]. The polished surfaces of the samples were covered with gold particles by the sputtering method, for the material to conduct electrons during analysis.

\subsection{Statistical analysis}

Statistical analysis was performed using SAS software (version 9.2, SAS Institute). After the analysis of ANOVA assumption, an assessment was defined by completely randomized design (CRD) and a comparison between the average values by Tukey test at $5 \%$ significance level. A statistical analysis of unbalanced data was carried out for comparison the physical and mechanical per-

\begin{tabular}{|c|c|c|c|c|c|}
\hline Composites & & MOR & $\mathrm{K}_{\mathrm{IC}}$ & $\mathrm{FE}$ & $\begin{array}{l}\text { Dynamic } \\
\text { MOE }\end{array}$ \\
\hline 28 days & $\begin{array}{l}8 \% \text { pulp }+1 \% \mathrm{NC} \\
9 \% \text { pulp }\end{array}$ & $\begin{array}{l}10 \\
10\end{array}$ & $\begin{array}{l}8 \\
8\end{array}$ & $\begin{array}{l}8 \\
8\end{array}$ & $\begin{array}{l}7 \\
6\end{array}$ \\
\hline Aged (200 cycles) & $\begin{array}{l}8 \% \text { pulp }+1 \% \text { NC } \\
9 \% \text { pulp }\end{array}$ & $\begin{array}{l}10 \\
10\end{array}$ & $\begin{array}{l}8 \\
8\end{array}$ & $\begin{array}{l}8 \\
8\end{array}$ & $\begin{array}{l}7 \\
6\end{array}$ \\
\hline
\end{tabular}
formance of the hybrid composites and composites reinforced only with pulp.

Table 3

Number of specimens used for mechanical tests. 


\section{Results and discussion}

\subsection{Pulp and nanofibrillated cellulose}

Fig. 1 presents the modifications in the fibers caused by the nanofibrillation. The Fig. 1A shows the surface of the pulp fiber with a diameter in microscale. Fig. 1B presents the fiber after nanofibrillation, which caused irreversible modification in the surface and opened hierarchical structure of the fiber, increasing its specific surface area.

The high specific surface area of the fibers improve the fibermatrix bonding when it is used as reinforcement in cement based composites, but this require more water demand to maintain an adequate rheological behavior in the extrusion process. The water/cement ratio of the hybrid composites (0.57) was higher than the ones reinforced with pulp (0.51).

Table 4 contains the morphological characteristics and specific density of the fibers before and after nanofibrillation. The higher specific density of the nanofibrillated cellulose compared to pulp is due to the high density of hydroxyl groups on the surface of the nanofibrillated cellulose, which can strongly interact and lead to agglomeration and formation of highly entangled network $[45,46]$, and therefore, increase the specific density of the fibers.

The decrease of length and width of the pulp after nanofibrillation is due the application of shear force generated by the discs of the grinder in the cell wall structure of the fiber. The cell wall structure of the fiber is formed by structured nanofibers in multilayer and hydrogen bonds, which were broked during nanofibrillation, producing nanoscale fibers from the pulp [47,21,32].

\subsection{Physical and microstructural characteristics of the composites}

The physical characteristics of the extruded hybrid composites with $8 \%$ of pulp $+1 \%$ of nanofibrillated cellulose and the composites reinforced with $9 \%$ of pulp at 28 days and after 200 cycles of immersion and drying cycles are showing in Table 5.

The results of water absorption and apparent void volume show that there were no statistical differences between both composites at 28 days. However, the hybrid composite at 28 days was statistically less dense than the reinforced with pulp. After accelerated aging, the water absorption and apparent porosity of the composites decreased due to continued hydration of the matrix and, eventually, the carbonation [40].

The extruded composites are heterogeneous materials compounded of domains of different materials (phases), in the length scale between hundreds of nanometers to several hundred microns. Thus, the physical characteristics obtained of the compos-
Table 4

Morphological and physical characteristics of pulp fibers and nanofibrillated cellulose $[21,33]$.

\begin{tabular}{llll}
\hline Fibers & Length & Width & $\begin{array}{l}\text { Specific } \\
\text { Density } \\
\left(\mathrm{g} . c m^{-3}\right)\end{array}$ \\
\hline $\begin{array}{c}\text { Bamboo organosolv } \\
\text { pulp [33] } \\
\begin{array}{c}\text { Nanofibrillated } \\
\text { cellulose [21] }\end{array}\end{array}$ & $0.8 \mathrm{~mm}$ & $19.8 \mu \mathrm{m}$ & 1.55 \\
\hline
\end{tabular}

ites are resulted of positives and negatives combined effects of differents microstructural parameters, such as specific surface area of the nanofibrillated cellulose, nanofiber packing density, particle packing density (Portland cement + limestone) and accelerated carbonation that contributed to refining pores of the matrix in the hybrid composites.

Each phase and its characteristics contributed of different way in the construction of the structure of the composites. The volume fraction and the distributions of the nanofiber and pulp fiber orientations as well as width, lengths and curvatures were important for these results. Besides, it is known that the particle packing density of the cement based composites and chemical additives had an important influence for decreasing water demand in the extrusion process.

The use of nanofibrillated cellulose of reduced hydrophilicity improves strength, but increases the water requirement for processing. However, the nanofibers can contribute to decrease the wall effect that occurs when the coarse particles create additional voids in the vicinity of the periphery, i. e., adding and dispersing nanofibers in the cement based microstructure helps filling up these voids.

The fatigue by immersion and drying caused defects (microcracks) in the aged hybrid composites and, therefore its water absorption and porosity were higher than composites reinforced only with pulp.

Fig. 2A present the hybrid composites at 28 days and Fig. 2B present the hybrid composites after 200 cycles of immersion and drying. The Fig. 2 shows the high surface area of the nanofibrillated cellulose and its ability to form bonds and improve the packing with the particles of the matrix (cement + limestone).

\subsection{Pore structure of hybrid composites and composites reinforced with pulp}

The cumulative pore size distribution and differential pore size distribution are shown in Fig. 3A and B, respectively.

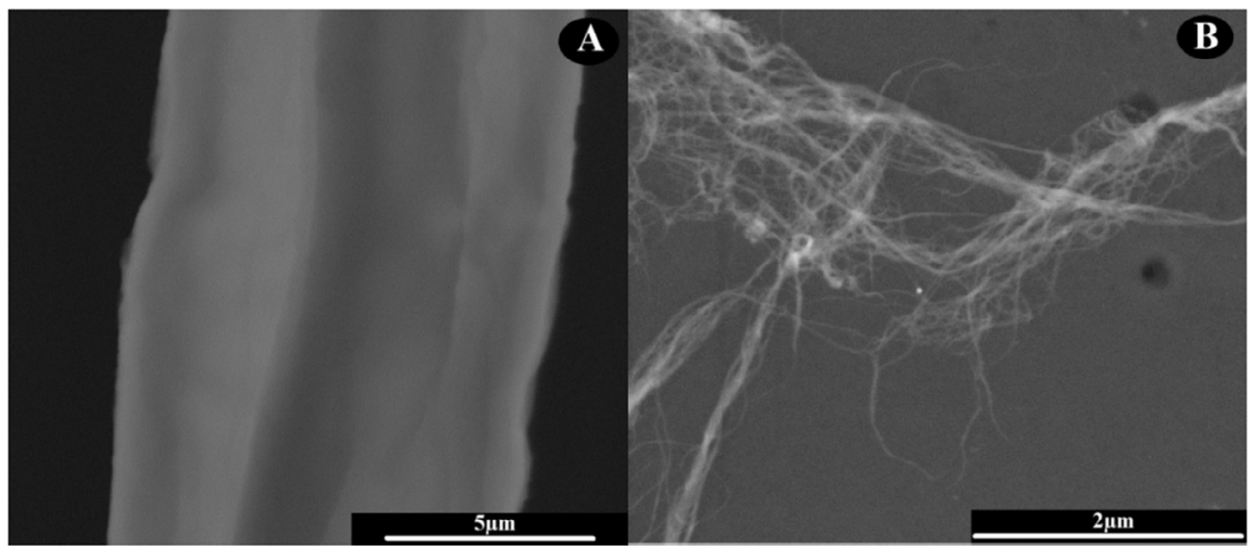

Fig. 1. Pulp fiber surface before nanofibrillation (A) and structural and morphological modifications after 10 nanofibrillation cycles (B) [21]. 
Table 5

Physical characteristics of hybrid composites and composites reinforced with pulp at 28 days and after accelerated aging.

\begin{tabular}{|c|c|c|c|c|}
\hline Composites & & Water Absorption (\%) & Apparent Void Volume (\%) & $\begin{array}{l}\text { Bulk Density } \\
\left(\mathrm{g} . \mathrm{cm}^{-3}\right)\end{array}$ \\
\hline 28 days & $\begin{array}{l}8 \% \text { pulp }+1 \% \mathrm{NC} \\
9 \% \text { pulp }\end{array}$ & $\begin{array}{l}22.6 a \\
22.6 a\end{array}$ & $\begin{array}{l}33.7 a \\
34.7 a\end{array}$ & $\begin{array}{l}1.49 \mathrm{a} \\
1.53 \mathrm{~b}\end{array}$ \\
\hline Aged (200 cycles) & $\begin{array}{l}8 \% \text { pulp }+1 \% \text { NC } \\
9 \% \text { pulp }\end{array}$ & $\begin{array}{l}17.3 \mathrm{a} \\
15.8 \mathrm{~b}\end{array}$ & $\begin{array}{l}26.8 a \\
24.6 b\end{array}$ & $\begin{array}{l}1.55 \mathrm{a} \\
1.55 \mathrm{a}\end{array}$ \\
\hline
\end{tabular}

* Average values followed by the same letters do not differ significantly by the Tukey test $(\mathrm{p}<.05)$.
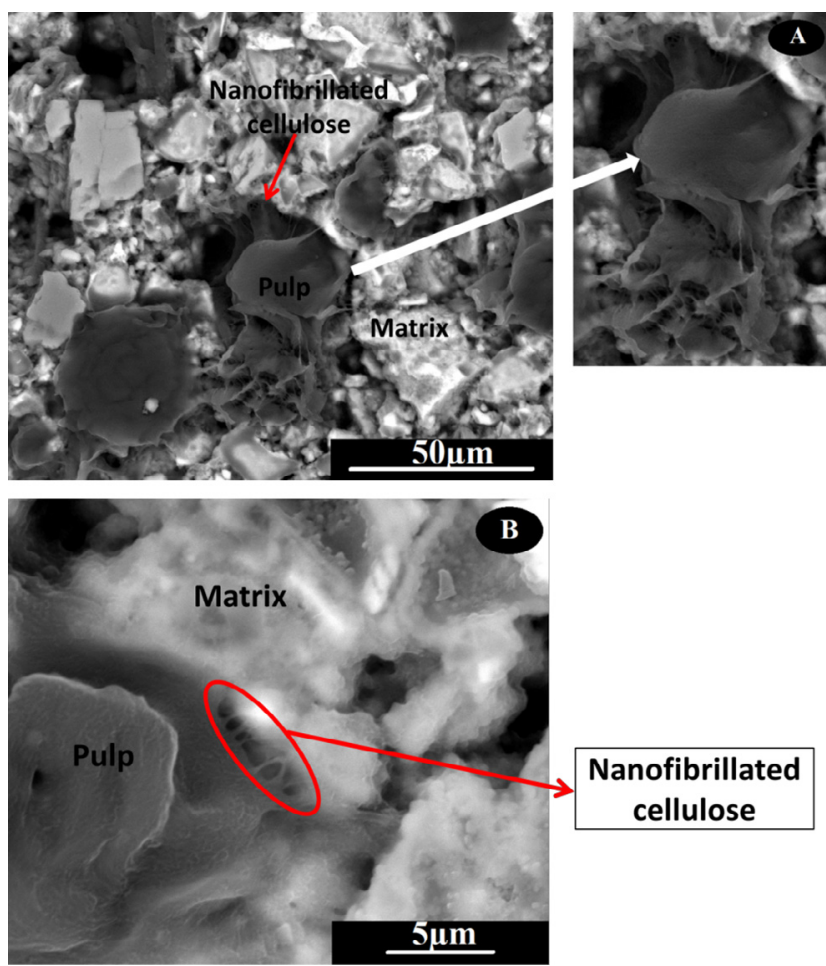

Fig. 2. Micrographs of polished surfaces of the hybrid composites at 28 days (A) and hybrid composites after 200 cycles of immersion and drying (B), indicating the fibers and the bonds of nanofibrillated cellulose with the matrix.

The porosity of cement-based materials is basically composed by capillary pores and gel pores. Capillary pores are permeable spaces, which are not filled by solid products of hydration cement. Whereas gel pores have direct relation with hydration products, calcium silicate hydrate (C-S-H) in particular. C-S-H is a colloidal amorphous gel and contains pores, which are called gel pores $[49,50]$.

The cumulative and pore size distribution curves show that hybrid composites and composites reinforced with pulp, at 28 days and after accelerated aging, are majority composed by small capillary pores, between 0.05 and $10 \mu \mathrm{m}$. The critical pore diameter of all composites are presented in the differential pore size distribution curves (Fig. 3B) between 5.76-0.30 $\mu \mathrm{m}$.

The curves show a higher volume of mercury intruded in aged composites than composites at 28 days, in the range of small capillary pores and gel pores. Additionally, the aged hybrid composites had a higher volume of mercury intruded in the large capillary pores. It's believed that the immersion and drying cycles caused higher incidence of pores in the nanoscale and also great defects $(10-100 \mu \mathrm{m})$ as result of microcracks caused by the aging cycles.

At the initial period of the immersion cycles, lignocellulosic pulp could absorb the water from the cementitious microstructure since the surrounding water concentration is greater than within the fibers. At a later stage of drying cycles, the moisture content within the fibers pulp dry out and thus, fibers shrink to a smaller size. The shrinkage of the fiber pulp generates microcracks between the fiber and cement matrix, which weakness interfacial transition zone.

On the other hand, It is well known that, during curing, the hydration product forms a shell around the unhydrated cement particle (i.e., the high density $\mathrm{CSH}$ ), slowing down the diffusion of water to its interior. This phenomenon limits the hydration rate and, as a result, the cores of the cement particles hydrate slowly. When nanofibrillated cellulose are present in the cement paste, it initially adhere to the cement particles and remain in the hydration product shell (i.e., the high density $\mathrm{CSH}$ ), they could form a path to transport water from the pore water to the inner unhydrated cement core. This may facilitate a larger portion of cement reacting with water compared with the cement pastes without
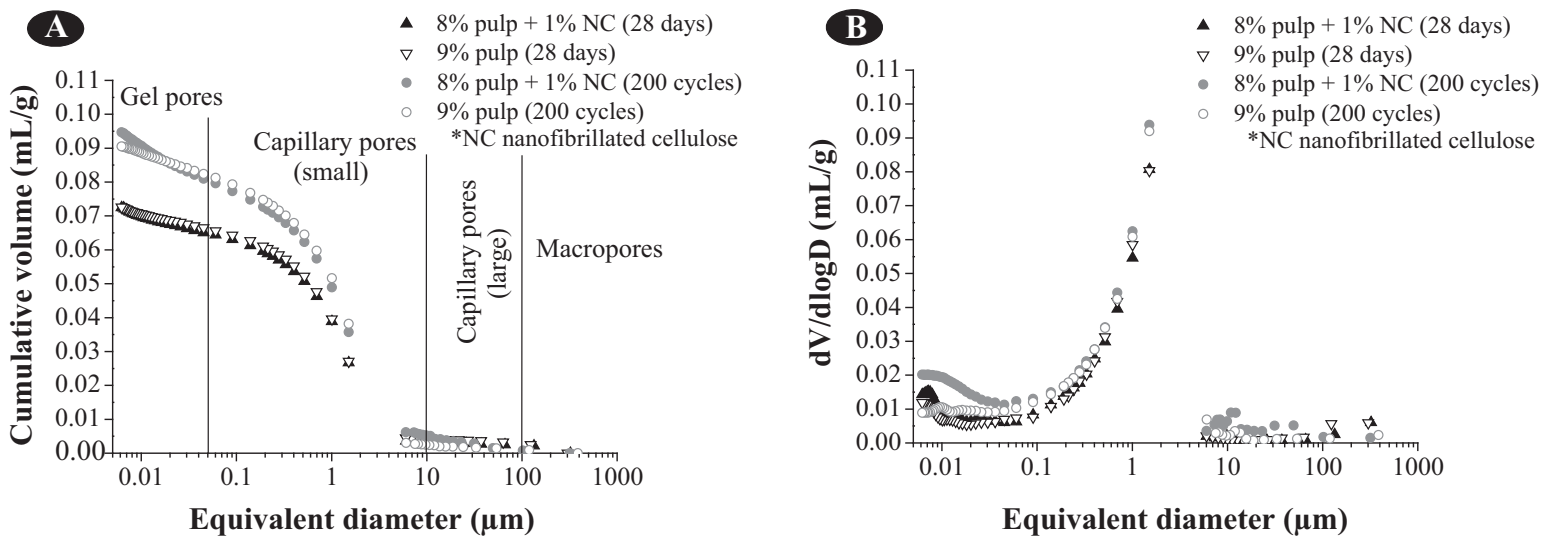

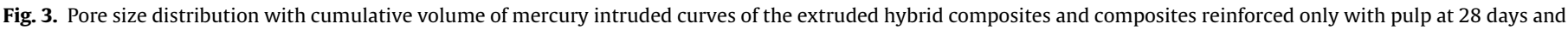
after accelerated aging. 
nanofibrillated cellulose. The mechanism of water molecules diffusing along the nanofibrillated pulp networks in the hydration products shell is here referred as short-circuit diffusion [51].

Thus, there is in the cementitiuous microstructure, reinforced with lignocellulosic pulp and nanofibrillated cellulose, a balance between both phenomena: formation of microcracks and formation of CSH in the interfacial transition zone.

\subsection{Mechanical performance of the composites}

The mechanical performance was evaluated from modulus of rupture (MOR), fracture toughness $\left(\mathrm{K}_{\mathrm{IC}}\right)$, fracture energy (FE) and dynamic Young's modulus (Dynamic MOE) of the extruded composites at 28 days and after 200 cycles of immersion and drying. The average values are listed in Table 6.

The value of the modulus of rupture of the hybrid composite is statistically higher in comparison to the composite without nanofibers at 28 days and after accelerated aging. The main contribution of the fibers in cement based composites takes place in the postcracking zone, where the fibers bridge across cracks that have propagated in the brittle matrix, and thus prevent catastrophic failure. For this reason, the modulus of rupture is directly associated to interface between fiber and matrix and performance of the fibers used as reinforcement, i.e., it indicates of the ability nanofibers to improvement the stress transfer along the specimen volume when subjected to load.

It is believed that at 10 nanofibrillation cycles the exposure of the S2 layer, after removing residual amorphous components of the fiber (hemicellulose and lignin), which contains proportionately more crystalline cellulose, increase the Young's modulus of the nanofibrillated cellulose [21]. Thus, the nanofibers contributed to increase physical and chemical adhesion; friction; mechanical anchorage induced by high surface area or by overall complex geometry in the flexural strength of the extruded composite. This contribution is shown in Fig. $2 \mathrm{~A}$ for hybrid composites at 28 days and in Fig. 2B for the aged hybrid composites.

As for fracture toughness, that represents the initial crack growth resistance in cement matrix, the results indicate that the nanofibers present a higher contribution to delay the onset of crack propagation, mainly after 200 cycles of immersion and drying. The results of fracture toughness shows that after accelerated aging the nanofibrillated cellulose preserved its ability to form bonds, once the fibers have remained undamaged. Fig. 2B shows that in the hybrid composite, the nanofibrillated cellulose continued acting as nanoreinforcement after accelerated aging.

The results of fracture toughness of the hybrid composites and composites reinforced only with pulp are higher than the results obtained by Santos et al. [40]. The authors produced composites, reinforced with $3 \%$ eucalyptus pulp and $2 \%$ of sisal fibers, produced by the extrusion method and subjected to accelerated carbonation curing in the supercritical condition. The authors also submitted the composite to 200 cycles of immersion and drying. The average results obtained by the Santos et al. [40] was $0.9 \mathrm{MPa} \cdot \mathrm{m}^{1 / 2}$ and $0.85 \mathrm{MPa}^{1 / 2}$, for the unaged and aged composites, respectively.

The dynamic Young's modulus of the aged hybrid composite was statistically higher than aged composites reinforced only with pulp. This results suggest that there was a more effective filling of pores with the hydration products and natural carbonation and consequently increased the rigidity of the aged hybrid composite. However, at 28 days there was no statistical difference in the dynamic Young's modulus of hybrid composites and composites reinforced with only pulp.

The values of fracture energy presented no statistical difference between hybrid composites and composites reinforced only with pulp at 28 days and after accelerated aging. These results suggest that, on the average, the modifications in the extruded composites with and without nanofibrillated cellulose, as well as the accelerated aging curing were no sufficient to differ the ability of such composites to absorb energy.

Fig. 4 shows the representative typical stress versus strain curves of the hybrid composites and composites reinforced only with pulp at 28 days and after accelerated carbonation.

Comparing the composites with and without nanofibrillated cellulose at 28 days, the hybrid composite presented a higher modulus of rupture. This result indicates the ability of the nanofibrillated cellulose to form bonding with the matrix, as showed in the Fig. $2 \mathrm{~A}$, and its potential to act as stress transfer bridges in the nano-cracking. However, the toughness was similar for both composites at 28 days and after accelerated carbonation, which can be observed by the similarity of the areas under the curves.

After accelerated aging, the modulus of rupture of the composites without nanofibers increased and the hybrid composites showed no significant difference. This performance indicates that there was no degradation in the fibers and in the composites by applying of the immersion and drying cycles.

\subsection{Correlation between mechanical and physical performance and microstructure of the composites}

The mechanical properties of the cement matrices are directly influenced by the volume, size and morphology of pores [49]. The relationship between porosity and strength in cement based materials is inverse, where, in general, pores are detrimental to strength. However, the interlayer space with the C-S-H structure and the small pores, which are within the influence of the van der Waals forces of attraction, and the impermeable pores, such as gel pores are not considered detrimental to strength. This is due the stress concentration and subsequent rupture on application of load that starts in the large capillary pores and in the microcracks, which are present in the matrix [52].

The physical results presented in Table 5 show a decrease of the apparent porosity based in the accelerated aging cycles, and a higher mechanical performance (MOR, $\mathrm{K}_{\mathrm{IC}}$ and Dynamic MOE) for such aged composites (hybrid and composites reinforced with pulp) (Table 6). As cement hydration and carbonation continues during accelerated aging, the apparent porosity decreases due the filling of permeable pores (capillary pores) with the hydration products and natural carbonation. Thus, the aged matrices of hybrid composites and of composites reinforced with pulp were densified and consequently, presented a higher stiffness, which is certified by the Dynamic MOE results.

Table 6

Mechanical performance of hybrid composites and composites reinforced with pulp at 28 days and after 200 cycles of immersion and drying.

\begin{tabular}{|c|c|c|c|c|c|}
\hline Composites & & MOR (MPa) & $\mathrm{K}_{\mathrm{IC}}\left(\mathrm{MPa} \mathrm{m}^{1 / 2}\right)$ & $\mathrm{FE}\left(\mathrm{J} \cdot \mathrm{m}^{-2}\right)$ & Dynamic MOE (GPa) \\
\hline 28 days & $\begin{array}{l}8 \% \text { pulp }+1 \% \text { NC } \\
9 \% \text { pulp }\end{array}$ & $\begin{array}{l}19.9 \mathrm{a} \\
14.8 \mathrm{~b}\end{array}$ & $\begin{array}{l}1.15 \mathrm{a} \\
1.02 \mathrm{a}\end{array}$ & $\begin{array}{l}421.8 a \\
394.7 a\end{array}$ & $\begin{array}{l}10.1 \mathrm{a} \\
9.6 \mathrm{a}\end{array}$ \\
\hline Aged (200cycles) & $\begin{array}{l}8 \% \text { pulp }+1 \% \text { NC } \\
9 \% \text { pulp }\end{array}$ & $\begin{array}{l}20.1 \mathrm{a} \\
17.8 \mathrm{~b}\end{array}$ & $\begin{array}{l}1.3 \mathrm{a} \\
1.0 \mathrm{~b}\end{array}$ & $\begin{array}{l}382.2 \mathrm{a} \\
379.1 \mathrm{a}\end{array}$ & $\begin{array}{l}13.4 \mathrm{a} \\
12.0 \mathrm{~b}\end{array}$ \\
\hline
\end{tabular}

* Average values followed by the same letters do not differ significantly by the Tukey test $(\mathrm{p}<.05)$. 


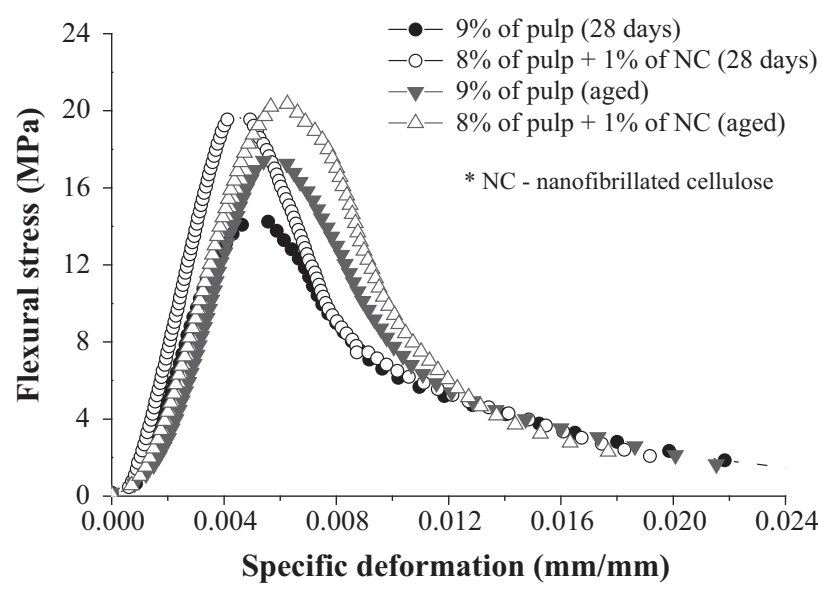

Fig. 4. Typical stress $x$ strain curves at under flexure tests of the hybrid composites and composites reinforced only with pulp at 28 days and after 200 cycles of immersion and drying.

However, the curves obtained from MIP analysis and presented in Fig. 3A and B, show a higher volume of mercury intruded in aged composites in comparison to composites at 28 days. As discussed in Section 3.3, the higher volume of mercury intruded in the capillary pores of aged composites, mainly for the hybrid composites, was due the defects caused (microcracks) by fatigue during immersion and drying cycles.

Despite this, the hybrid aged composites have a higher porosity in the range of gel pores. Gel pores are specifically associated with the $\mathrm{C}-\mathrm{S}-\mathrm{H}$ gel phase, which is the primary hydration product of cement [49]. The apparent presence of C-S-H in hybrid aged composites can provide an indicative of better mechanical performance of these composites, once C-S-H gel contributes to the long-term strength of cement matrix. Additionally, C-S-H is nanoporous component with high specific surface area [53,54] that can have favoured the packing with nanofibrillated cellulose in the hybrid composites.

\section{Conclusion}

The results of this work showed that, in general, at 28 days the extruded composites with and without nanofibrillated cellulose presented a similar physical performance. The high specific surface area of the nanofibrillated cellulose allowed the improvement of the packing of the nanofibers with the particles of the matrix (cement + limestone). Hence, the water absorption and apparent void volume of the hybrid composites were no higher than composites without nanofibers at 28 days, although the higher water/ cement ratio of the composites with nanofibers.

Additionally, the extrusion process contributed significantly to the mechanical performance of the hybrid composites due to the ability of this process to distribute the fibers and align them in the most favorable direction to withstand the flexural stresses.

The content of $1 \%$ of nanofibrillated cellulose associated with $8 \%$ of pulp was sufficient to form stress transfer bridges in the nano and micro cracking, which was confirmed by the higher modulus of rupture of the hybrid composites. Mechanical tests have also shown that nanofibrillated cellulose no presented degradation after accelerated aging of composites, once the values of the modulus of rupture and fracture toughness of the hybrid composites were not decreased.

The accelerated carbonation curing contributed to the densification of the matrix and increase the dynamic modulus of elasticity of the composites after accelerated aging. Although nanofibrillated cellulose works to increase the mechanical strength of extruded fiber cement, it does not contribute to the increased toughness.

Considering to explained previously and the intrinsic characteristics of the nanofibrillated cellulose, such as, abundance worldwide, renewable resource and mainly have a high aspect ratio and specific surface area, this vegetable material showed to be a promising material for use as nanoreinforcement of the extruded hybrid cement-based composites.

\section{Acknowledgments}

The authors were supported by grants offered by Research Foundation of the Sao Paulo State - FAPESP, Brazil (Grants $\mathrm{n}^{\mathrm{o}}$ : 2011/01128-5, 2012/51467-3, 03823/2013 and 2015/21079-0), Coordination for the Improvement of High Education Personnel CAPES, Brazil (Grant $n^{\circ} 03884 / 2014$ ) and National Council for Scientific and Technological Development - CNPq, Brazil (Grants $n^{\circ}$ : 142082/2011-2).

\section{References}

[1] G. Constantinides, F.J. Ulm, The nanogranular nature of $\mathrm{C}-\mathrm{S}-\mathrm{H}, \mathrm{J}$. Mech. Phys. Solids 55 (2007) 64-90, https://doi.org/10.1016/j.jmps.2006.06.003.

[2] J.W. Bullard, H.M. Jennings, R.A. Livingston, A. Nonat, G.W. Scherer, S.S. Jeffrey, K.L. Scrivener, J.J. Thomas, Mechanisms of cement hydration, Cem. Concr. Res. 41 (2011) 1208-1223, https://doi.org/10.1016/j.cemconres.2010.09.011.

[3] R.N. Swamy, Natural Fibre-Reinforced Cement Concrete. Concrete Technology and Design, Blackie Academic \& Professional, London, 1988.

[4] A. Bentur, S. Mindess, Introduction, in: A. Bentur, S. Mindess (Eds.), Fibre Reinforced Cementitious Composites, second ed., Taylor \& Francis, New York, 2007, pp. 1-10.

[5] A.M. Brandt, Reinforcement of cement-based composites, in: A.M. Brandt (Ed.), Cement-based COMPOSITES: Materials, Mechanical Properties and Performance, second ed., Taylor \& Francis, New York, 2009, pp. 110-136.

[6] T. Tan, S.F. Santos, H. Savastano Jr., W.O. Soboyejo, Fracture and resistancecurve behavior in hybrid natural fiber and polypropylene fiber reinforced composites, J. Mater. Sci. 47 (2012) 2864-2874, https://doi.org/10.1007/ s10853-011-6116-1.

[7] R. Hamzaoui, S. Guessasma, B. Mecheri, A.M. Eshtiaghi, A. Bennabi, Microstructure and mechanical performance of modified mortar using hemp fibres and carbon nanotubes, Mater. Design 56 (2014) 60-68, https://doi.org/ 10.1016/j.matdes.2013.10.084.

[8] C.G. Hoyos, E. Cristia, A. Vázquez, Effect of cellulose microcrystalline particles on properties of cement based composites, Mater. Design 51 (2013) 810-818, https://doi.org/10.1016/j.matdes.2013.04.060.

[9] H.Y. Kordkheili, S. Hiziroglu, M. Farsi, Some of the physical and mechanical properties of cemetn composites manufactured from carbon nanotubes and bagasse fiber, Mater. Design 33 (2012) 395-398, https://doi.org/10.1016/ j.matdes.2011.04.027.

[10] J. M. Makar, J. C. Margeson, J. Luh, Carbon nanotube/cement composite-early results and potential applications, in: International Conference on Construction Materials: Performance, Innovation and Structural Implications, 3. Proceedings... Institute for Research in Construction, National Research Council Canada, Ottawa, 2005, pp. 1-10.

[11] G.Y. Li, P.M. Wang, X. Zhao, Mechanical behavior and microstructure of cement composites incorporating surface-treated multi-walled carbon nanotubes, Carbon 43 (2005) 1239-1245, https://doi.org/10.1016/j.carbon.2004.12.017.

[12] G. Yakovlev, J. Kerienè, A. Gailius, I. Girniene, Cement based foam concrete reinforced by carbon nanotubes, Mater. Sci. 12 (2006) 147-151.

[13] G.Y. Li, P.M. Wang, X. Zhao, Pressure-sensitive properties and microstructure of carbon nanotube reinforced cement composites, Cem. Concr.Compos. 29 (2007) 377-382, https://doi.org/10.1016/j.cemconcomp.2006.12.011.

[14] M.S. Konsta-Gdoutos, Z.S. Metaxa, S.P. Shah, Multi-scale mechanical and fracture characteristics and early-age strain capacity of high performance carbon nanotube/cement nanocomposites, Cem. Concr. Compos. 32 (2010) 110-115, https://doi.org/10.1016/j.cemconcomp.2009.10.007.

[15] M.J. Hanus, A.T. Harris, Nanotechnology innovations for the construction industry, Prog. Mater. Sci. 58 (2013) 1056-1102, https://doi.org/10.1016/j. pmatsci.2013.04.001.

[16] O. Galao, F.J. Baeza, E. Zornoza, P. Garcés, Strain and damage sensing properties on multifunctional cement composites with CNF admixture, Cem. Concr. Compos. 46 (2014) (2014) 90-98, https://doi.org/10.1016/j. cemconcomp.2013.11.009.

[17] A.F. Turbak, F.W. Snyder, K.R. Sandberg, Microfibrillated cellulose, a new cellulose product: properties, uses and commercial potential, J. Appl. Polym. Sci. Symp. 37 (1983) 815-827.

[18] A.N. Nakagaito, H. Yano, The effect of morphological changes from pulp fiber towards nano-scale fibrillated cellulose on the mechanical properties of high- 
strength plant fiber based composites, Appl. Phys. A Mater. Sci. Process. 78 (2004) 547-552, https://doi.org/10.1007/s00339-003-2453-5.

[19] I. Siró, D. Plackett, Microfibrillated cellulose and new nanocomposite materials: a review, Cellulose 17 (2010) 459-494, https://doi.org/10.1007/ s10570-010-9405-y.

[20] M.L. Hassan, A.P. Mathew, E.A. Hassan, N. El-Wakil, K. Oksman, Nanofibers from bagasse and rice straw: process optimization and properties, Wood Sci. Technol. 46 (2012) 193-205, https://doi.org/10.1007/s00226-010-0373-z.

[21] V.C. Correia, V. Santos, M. Sain, S.F. Santos, A.L. Leão, H. Savastano Jr., Grinding process for the production of nanofibrillated cellulose based on unbleached and bleached bamboo organosolv pulp, Cellulose (2016) 1-17, https://doi.org/ 10.1007/s10570-016-0996-9.

[22] S. Kamel, Nanotechnology and its applications in lignocellulosic composites, a mini review, Express Polym. Lett. 1 (2007) 546-575, https://doi.org/ 10.3144/expresspolymlett.2007.78.

[23] D.J. Gardner, G.S. Oporto, R. Mills, M.A.S.A. Samir, Adhesion and surface issues in cellulose and nanocellulose, J. Adhes. Sci. Technol. 22 (2008) 545-567, https://doi.org/10.1163/156856108X295509.

[24] M. Ardanuy, J. Claramunt, R. Arévalo, F. Parés, Nanofibrillated cellulose (NFC) as a potential reinforcement for high performance cement mortar composites, BioResources 73 (2012) 3883-3894.

[25] O. Onuaguluchi, D.K. Panesar, M. Sain, Properties of nanofibre reinforced cement composites, Constr. Build. Mater. 63 (2014) 119-124, https://doi.org/ 10.1016/j.conbuildmat.2014.04.072.

[26] N. Banthia, N. Nandakumar, Crack growth resistance of hybrid fiber reinforced cement composites, Cem. Concr. Compos. 25 (2003) 3-9, https://doi.org/ 10.1016/S0958-9465(01)00043-9.

[27] R.S.P. Coutts, Fibre-matrix interface in air-cured wood-pulp fibre- cement composites, J. Mater. Sci. Lett. 6 (1987) 140-142, https://doi.org/10.1007/ BF01728964.

[28] H. Savastano Jr., P.G. Warden, R.S.P. Coutts, Mechanically pulped sisal as reinforced in cementitious matrices, Cem. Concr. Compos. 25 (2003) 311-319, https://doi.org/10.1016/S0958-9465(02)00055-0.

[29] H. Savastano Jr., S.F. Santos, M. Radonjic, W.O. Soboyejo, Fracture and fatigue of natural fibre-reinforced cementitious composites, Cem. Concr. Compos. 31 (2009) 232-243, https://doi.org/10.1016/j.cemconcomp.2009.02.006.

[30] J.A. Melo Filho, F.A. Silva, R.D. Toledo Filho, Degradation kinetics and aging mechanisms on sisal fiber-cement composite systems, Cem. Concr. Compos. 40 (2013) 30-39, https://doi.org/10.1016/j.cemconcomp.2013.04.003.

[31] A.E.F.S. Almeida, G.H.D. Tonoli, S.F. Santos, H. Savastano Jr., Improved durability of vegetable fiber reinforced cement composite subject to accelerated carbonation at early age, Cem. Concr. Compos. 42 (2013) 49-58, https://doi.org/10.1016/j.cemconcomp.2013.05.001.

[32] V.C. Correia, S.F. Santos, G.H.D. Tonoli, H. Savastano Jr., Characterization of vegetable fibers and their application in cementiotious composites. in: K. A. Harries, B. Sharma, (Eds.), Nonconventional and Vernacular Construction Materials: Characterisation, Properties and Applications, Woodhead Publishing, Duxford, 2016, pp. 83-110. https://doi.org/10.1016/B978-0-08100038-0.00004-4

[33] V.C. Correia, S.F. Santos, G. Mármol, A.A.S. Curvelo, H. Savastano Jr., Potential of bamboo organosolv pulp as reinforcement element in fiber-cement, Constr. Build. Mater. 72 (2014) 65-71, https://doi.org/10.1016/ j.conbuildmat.2014.09.005.

[34] Technical Association of the Pulp and Paper Industry, Tappi Useful Method T 204 cm-97: Solvent Extractives of Wood and Pulp, Tappi Press, Peachtree Corners, 1997.

[35] Technical Association of the Pulp and Paper Industry, Tappi Test Methods, T 222 om-98: Acid-insoluble Lignin in Wood and Pulp, Tappi Press, Peachtree Corners, 1998

[36] J.P.S. Morais, M.F. Rosa, J.M. Marconcini, Procedimentos para análise lignocelulósica. Embrapa, Campina Grande, 2010.(In Portuguese)
[37] G.H.D. Tonoli, E. Fuente, C. Monte, H. Savastano Jr., F.A. Rocco Lahr, A. Blanco Effect of fibre morphology on flocculation of fibre-cement suspensions, Cem. Concr. Res. 39 (2009) 1017-1022, https://doi.org/10.1016/j. cemconres.2009.07.010.

38] American Society for Testing and Materials. ASTM C150M-11: Standard Specification for Portland Cement, ASTM International, West Conshohocken, 2011. https://doi.org/10.1520/C0150_C0150M-16E01.

[39] R.S. Teixeira, G.H.D. Tonoli, S.F. Santos, J. Fiorelli, H. Savastano Jr., F.A. Rocco Lahr, Extruded cement based composites reinforced with sugar cane bagasse fibres, Key Eng. Mater. 517 (2012) 450-457, https://doi.org/10.4028/ www.scientific.net/KEM.517.450.

[40] S.F. Santos, R. Schmidt, A.E.F.S. Almeida, G.H.D. Tonoli, H. Savastano Jr. Supercritical carbonation treatment on extruded fibre-cement reinforced with vegetable fibres, Cem. Concr. Compos. 56 (2015) 84-94, https://doi.org 10.1016/j.cemconcomp.2014.11.007.

[41] European Standard. EN 494: Fibre-Cement Profiled Sheets and Fittings for Roofing-Products Specification and Test Methods, 1994

[42] American Society for Testing and Materials. ASTM E 1876-07: Standard Test Method for Dynamic Young's Modulus, Shear Modulus and Poisson's Ratio by Impulse Excitation of Vibration, ASTM International, West Conshohocken, 2007. https://doi.org/10.1520/E1876-15.

[43] American Society for Testing and Materials. ASTM C 948-82: Test method for dry and wet bulk density, water absorption, and apparent porosity of thin sections of glass-fibre reinforced concrete, ASTM International, West Conshohocken, 1982. https://doi.org/10.1520/C0948-81R16.

[44] S. Diamond, Mercury porosimetry: an inappropriate method for the measurement of pore size distributions in cement-based materials, Cem Concr. Res. 30 (2000) 1517-1520, https://doi.org/10.1016/S0008-8846(00 00370-7.

[45] T. Zimmermann, E. Pohler, T. Geiger, Cellulose fibrils for polymer reinforcement, Adv. Eng. Mater. 6 (2004) 754-761, https://doi.org/10.1002/ adem.200400097.

[46] S. Alila, I. Besbes, M.R. Vilar, P. Mutjé, S. Boufi, Non-woody plants as raw materials for production of microfibrillated cellulose (MFC): a comparative study, Ind. Crop. Prod. 41 (2013) 250-259, https://doi.org/10.1016/j indcrop.2012.04.028

[47] S. Iwamoto, A.N. Nakagaito, H. Yano, Nano-fibrillation of pulp fibers for the processing of transparent nanocomposites, Appl. Phys. A Mater. Sci. Process. 89 (2007) 461-466, https://doi.org/10.1007/s00339-007-4175-6.

[48] K. Missoum, M.N. Belgacem, J. Bras, Nanofibrillated Cellulose Surface Modification: a review, Materials 6 (2013) 1745-1766, https://doi.org 10.3390/ma6051745.

[49] H.M. Jennings, J.W. Bullard, J.J. Thomas, J.E. Andrade, J.J. Chen, G.W. Scherer, Characterization and Modeling of Pores and Surfaces in Cement Paste: Correlations to Processing and Properties, J. Adv. Concr. Technol. 6 (2008) 5 29. doi.org/10.3151/jact.6.5.

50] J. Zhou, G. Ye, K.V. Breugel, Characterization of pore structure in cement-based materials using pressurization-depressurization cycling mercury intrusion porosimetry (PDC-MIP), Cem. Concr. Res. 40 (2010) 1120-1128, https://doi org/10.1016/j.cemconres.2010.02.011.

[51] Y. Cao, P. Zavaterri, J. Youngblood, W.J. Weiss, The influence of cellulose nanocrystal additions on the performance of cement paste, Cem. Concr. Compos. $56 \quad$ (2015) 73-83, https://doi.org/10.1016/j. cemconcomp.2014.11.008.

[52] P.K. Mehta, P.J.M. Monteiro, Concrete: Microstructure, Properties, and Materials, third ed., McGraw-Hill Professional Publishing, New York, 2006 https://doi.org/10.1036/0071462899.

[53] H.F.W. Taylor, Nanostructure of C-S-H: current status, Adv. Cem. Based Mater. 1 (1993) 38-46, https://doi.org/10.1016/1065-7355(93)90006-A.

[54] H.F.W. Taylor, Cement Chemistry, second ed., Thomas Telford Publishing, London, 1997. 